EDITORIAL

\title{
Lipodystrophy Associated with HIV/ART and Cardiovascular Risk Factors
}

\author{
Claudio Leinig Pereira da Cunha \\ Universidade Federal do Paraná, Paraná, PR - Brazil \\ Editorial referring to the article: Self-reported HIV/HAART-associated lipodystrophy and modifiable risk factors for cardiovascular disease
}

Before effective antiretroviral therapy (ART) became available, patients with advanced acquired immunodeficiency syndrome had devastating losses and their metabolic profile was characterized by reduced cholesterol levels. Since introduction of ART, numerous studies have reported changes in body composition with accumulation of central fat and loss of peripheral fat. The term "human immunodeficiency virus (HIV)-associated lipodystrophy syndrome" was then coined, which was soon recognized as several phenotypes that varied from person to person, rather than a unique syndrome. While some individuals had solely lipoatrophy, others had fat accumulation with varied presentation or a mixed condition of the two morphological patterns. ${ }^{1}$

Lipoatrophy involves loss of subcutaneous fat in the face, arms, legs, abdomen, and buttocks. Abdominal fat accumulation is featured mainly by excess visceral fat and consequent increased waist circumference, but also in the dorsal cervical region ("buffalo hump"), trunk, breasts (in both women and men), and lipomas of the upper extremities. ${ }^{2}$

The prevalence of lipodystrophy syndrome is controversial, varying from $10 \%$ to $80 \%$ of HIV patients. ${ }^{3}$ This wide variation may be due to conceptual and methodological issues (e.g. self-reports or objective measures), characteristics of the patients (age, genetics, lifestyle), or treatment (type and duration). ${ }^{3}$

In an interesting study conducted by Jacobson et al. ${ }^{4}$ on 452 HIV-infected patients, the prevalence of lipoatrophy, fat accumulation, and a mixed lipodystrophy was 35\%,

\section{Keywords}

Lypodystrophy; Retroviridae; HIV-Associated Lypodystrophy Syndrome; Cardiovascular Diseases; Risk Factors.
$44 \%$ and $14 \%$, respectively. Body fat was measured objectively. Lipoatrophy was defined as a triceps skinfold measurement less than the tenth percentile for sex and age, according to the National Health and Nutrition Examination Survey. Fat accumulation was defined as a waist-to-hip ratio of $>0.95$ for men and of $>0.85$ for women as a surrogate for intra-abdominal fat. ${ }^{4}$

Several factors may influence the occurrence of different forms of lipodystrophy. Data have suggested that the main risk factor for lipodystrophy is the exposure to nucleoside reverse transcriptase inhibitors (NRTIs), especially stavudine and zidovudine. ${ }^{5}$ Other characteristics of the patients and the virus can also affect lipodystrophy phenotypes, such as low fat mass, advanced age, high viral load, and low CD4 counts in the beginning of therapy. ${ }^{4}$ Fat accumulation was not associated with any retroviral therapy regimen, and showed a relationship with increasing age and female sex. ${ }^{2}$

Lipodystrophy and fat accumulation have been associated with abnormalities of lipid and glucose metabolism. ${ }^{6}$ The development of visceral obesity, insulin resistance and atherogenic lipid profile reinforces the concept of an increased cardiovascular risk in HIV-infected individuals, since these are well-recognized risk factors. ${ }^{7}$

The association between lipodystrophy and metabolic dysfunction can be related to adipokines. Adipokines, such as adiponectin, leptin, and resistin are involved in many metabolic pathways. Patients with HIV infection and lipodystrophy have low adiponectin levels, favoring the development of insulin resistance. ${ }^{8}$ Lipoatrophy is also associated with hypoleptinemia, which, in turn, is related to insulin resistance. Lipoatrophy and diabetes mellitus have been observed in HIV patients in ART and attributed to genetic changes in resistin. ${ }^{9}$ In patients with HIV and lipodystrophy, the waist-hip ratio was the main indicator of fasting hyperinsulinemia. ${ }^{10}$ 
Atherogenic lipid profiles have been associated with changes in body fat in HIV-infected patients. ${ }^{11} \mathrm{~A}$ study on the relationship between regional body fat distribution and lipid levels has shown that the atherogenic profile was more common in HIV patients, particularly in those with increased visceral fat, reduced subcutaneous fat in the legs, increased triglyceride levels and reduced HDL cholesterol levels. ${ }^{12}$

Arterial hypertension seems to be more prevalent in HIV-infected than in HIV-uninfected individuals, especially in HIV patients using ART for at least two years. No specific therapeutic agent has been associated with hypertension. ${ }^{13}$

Individuals with HIV infection have lower rates of smoking compared with the general population ( $42 \%$ vs. $21 \%) .{ }^{14} \mathrm{HIV}$-infected smokers have higher cardiovascular

\section{References}

1. Carr A, Samaras K, Chisholm DJ, Cooper DA. Pathogenesis of HIV-1protease inhibitor-associated peripheral lipodystrophy, hyperlipidaemia and insulin resistance. Lancet. 1998;351(9119):1881-3.

2. Bacchetti P,Gripshover B, Grunfeld C, Heymsfield S, McCreath H, Osmond D, et al. Fat distribution in men with HIV infection. J Acq Immune Defic Syndr. 2005;40(2):121-31.

3. Tien PC, Cole SR, Williams CM, Li R, Justman JE, Cohen MH, et al. Incidence of lipoatrophy and lipohypertrophy in the women's interagency HIV study. J Acquir Immune Defic Syndr. 2003;34(5):461-6.

4. Jacobson DL, Knox T, Spiegelman D, Skinner S, Gorbach S, Wanke C. Prevalence of, evolution of, and risk factors for fat atrophy and fat deposition in a cohort of HIV-infected men and women. Clin Infect Dis. 2005;40(12):1837-45.

5. Mallal SA, John M, Moore CB, James IR, McKinnon EJ. Contribution of nucleoside analogue reverse transcriptase inhibitors to subcutaneous fat wasting in patients with HIV infection. AIDS. 2000;14(10):1309-16.

6. Gan SK, Samaras K, Carr A, Chisholm D. Anti-retroviral therapy, insulin resistance and lipodystrophy. Diabetes Obes Metab. 2001;3(2):67-71.

7. Després JP. Health consequences of visceral obesity. Ann Med. 2001;33(8):534-41.

8. Addy CL, Gavrila A, Tsiodras S, Brodovicz K, Karchmer AW, Mantzoros CS. Hypoadiponectinemia is associated with insulin resistance, hypertriglyceridemia, and fat redistribution in human immunodeficiency virus-infected patients treated with highly active antiretroviral therapy. J Clin Endocrinol Metab. 2003;88(2):627-36. mortality rates, with estimates of 12.3 years of life lost to smoking compared with HIV-infected non-smokers. ${ }^{14}$

The data presented in the study by Jardim et al.15 in the present issue of the International Journal of Cardiovascular Sciences describe well this association between lipodystrophy and HIV/ART. The study presents the prevalence of this syndrome in Brazil and the results indicate that lipodystrophy is not associated with modified cardiovascular risk factors, but rather with female sex, family history of cardiovascular disease and time of HIV infection. The authors did not compare the occurrence of cardiovascular risk factors to that in the general population and did not evaluate the influence of lipodystrophy on the clinical course of these patients. Since data collection was made approximately 10 years ago, it would be useful if these patients were reevaluated to define the influence of lipodystrophy on survival.

9. Ranade K, Geese WJ, Noor M, Flint O, Tebas P, Mulligan K, et al. Genetic analysis implicates resistin in HIV lipodystrophy. AIDS. 2008;22(13):1561-8.

10. Meininger G, Hadigan C, Rietschel P, Grinspoon S. Body-composition measurements as predictors of glucose and insulin abnormalities in HIV-positive men. Am J Clin Nutr. 2002;76(2):460-5.

11. Grinspoon S, Carr A. Cardiovascular risk and body-fat abnormalities in HIV-infected adults N Engl J Med. 2005;352(1):48-62.

12. Wohl D, Scherzer R, Heymsfield S, Simberkoff M, Sidney S, Bacchetti $\mathrm{P}$, et al. The association of regional adipose tissue with lipid and lipoprotein levels in HIV-infected men. J Acquir Immune Defic Syndr. 2008;48(1):44-52.

13. Seaberg EC, Muñoz A, Lu M, Detels R, Margolick JB, Riddler SA, et al. Association between highly active antiretroviral therapy and hypertension in a large cohort of men followed from 1984 to 2003. AIDS. 2005;19(9):953-60.

14. Helleberg M, Afzal S, Kronborg G, Larsen CS, Pedersen G, Pedersen C, et al. Mortality attributable to smoking among HIV-1-infected individuals: a nationwide population-base cohort study. Clin Infect Dis. 2013;56(5):727-34.

15. Jardim TV, Cardoso RC, Santos ASAC, Falco MO, Silveira EA. Selfreported HIV/HAART-associated lipodystrophy and modifiable risk factors for cardiovascular disease. Int J Cardiovasc Sci. 2020; 33(6):606-615. 